\title{
Comparative Analysis of the Influence of Music Training at Home and Abroad on Language Ability
}

\author{
Shen Shiya \\ Institute of Development and Psychology, Education, Wuhan University, School of Marxism, \\ Wuhan, China, 430072
}

Keywords: music training, phonological awareness, speech perception, language production, speech understanding, speech memory

Abstract: In recent years, the impact of music training on cognitive ability has received much attention. One of the important parts is the influence of music training on language ability. The research on the impact of music training on language ability in recent years was reviewed in this paper. From the five aspects of phonological awareness, speech perception, language production, speech comprehension and verbal memory, a comparative analysis of domestic and foreign research was carried out. As a result, differences in findings and vacancies were discovered, providing direction and reference for future education and research.

\section{Introduction}

From the early research, musicians have advantages in terms of language ability, space ability and mathematics ability compared with non-musicians. The difference is mainly that musicians have received long-term, professional music training. Music training, especially instrumental performance training, is an intensive activity involving multiple senses, involving hearing, vision, body sensation, etc. Musical training leads to changes in brain structure and function (Jiang Cunmei, Music Psychology, 2016: 198).

In reality, more and more children are receiving music training, and more music courses are entering school education. Parents hope to develop children's brains through music learning. Then, whether music training can improve people's cognitive function will attract people's attention. The study of the influence of music training on language ability is more concerned.

\section{Research progress}

\subsection{Music training and phonological awareness}

Phonological awareness is a meta-language ability, the ability to perceive and manipulate speech, and has a close correlation with reading ability. (Tunmer \& Herriman, 1984)

Escalda, Lemos, and França (2011) found that 5-year-old children's music experience has improved auditory and meta-language skills while enabling children to better process phonological awareness. Subsequent research has also provided evidence for this, including support for cognitive 
nerves. For example, the emergence of musical perception and phonological awareness has parallel auditory perception mechanisms (Lathroum, 2011). Early music training enhances and maintains acute neurological processing in the auditory center even in old age (White-Schwoch, Carr, Anderson, Strait, \& Kraus, 2013), and music training improves brain circuits in music and language processing (Habib, Lardy, Desiles, Commeiras, Chobert \& Besson, 2016). In addition, the effects of music training have been validated in different populations. For example, in preschool children, there is a significant positive correlation between music training time and speech coding (WhiteSchwoch et al., 2013). The promotion of speech coding for speech coding has also been proven in young (Parbery-Clark, Anderson, Hittner, \& Kraus, 2012a; Parbery-Clark, Hittner, \& Kraus, 2012b) and middle-aged people (Parbery-Clark et al., 2012a).

Recently, Flaugnacco (2015) studied children with dyslexia and found that music training can improve reading and speech skills. Patscheke, Degé and Schwarzer's (2016) longitudinal studies of children aged 4-6 in immigrant families found that speech training and music training have a significant impact on phonological awareness. The influence of music training is more significant, but physical training has no significant effect on phonological awareness. Li Wenhui, Suo Changqing, Danfei and Zhou Tingting (2016) found that the level of phonological awareness of the music training group was significantly higher than that of the non-music group.

However, Kempert et al. (2016) studied German children and found that speech training had a significant impact on phonological awareness, while music training had no significant effect on phonological awareness.

The above studies show that the differences in the language of the test group, the length of the music training, and the way the music is trained may result in differences in results.

\subsection{Music training and language understanding}

The study of the impact of music training on speech understanding focuses on two aspects: vocabulary understanding and paragraph understanding. Many studies have shown that children who have had music training have better performance in vocabulary understanding than children who have not had music training (Forgeard et al., 2008; Schellenberg, 2011; Swaminathan \& Gopinath, 2013). There are also longitudinal studies that provide evidence for this. Schellenberg (2004) found that the scores of speech comprehension in music groups were significantly higher than those in non-music groups after 36 weeks of music training for 6-year-old children.

In terms of paragraph understanding, Lowe (1995) found that music training has no significant effect on the improvement of children's paragraph comprehension. The results of this study were revalidated by Register, Darrow, Swedberg \& Standley (2007), but they also found that students with dyslexia had significantly improved paragraph comprehension.

Later, Long (2014)'s follow-up study on 6-month music training for children with speech disabilities also showed that the participants' ability to understand paragraphs was significantly improved.

In general, music training promotes the improvement of language comprehension, but the length of music training for different groups of people needs to be further studied.

\subsection{Music training and speech perception}

Speech perception, the auditory system, records the sounds of speech as it is, and then converts these vibrations into a sequence of sounds. (Margaret Matlin, Cognitive Psychology, 2016: 28)

Musical perception and speech perception depend on similar auditory time processing mechanisms (Goswami, 2012; Tallal \& Gaab, 2006). This view has been validated in children (Woodruff, White-Schwoch, Tierney, Strait, \& Kraus, 2014), adolescents (Tierney \& Kraus, 2013) 
and adults (Manon, Cooper, \& Griffiths, 2013). The researchers found that subjects with impairment in reading ability, their rhythm ability will be lower than normal (Overy, Nicolson, Fawcett, \& Clarke, 2003). Interventions with dyslexia focused on rhythm and time processing can improve their speech skills, and long-term intervention studies have found that music training can improve children's speech perception (Flaugnacco et al., 2015).

Other researchers have found that music training is associated with first language perception (Zuk et al., 2013) and reading ability (Corrigall \& Trainor, 2014) and the fluency of the second language (Swaminathan \& Gopinath, 2013).

Domestic Wang Mengyuan, Ning Ruijing and Zhang Xueyan (2015) found that music training plays an important role in delaying the decline of speech perception ability of the elderly.

However, the study by Swaminathan and Schellenberg (2017) found that there is a correlation between music training and melody and rhythm perception, and there is no correlation between perception of foreign language factors.

The existing music, cognitive and motivational factors in previous research have not been controlled, which means that the causal relationship between the two is not clear.

\subsection{Music training and language production}

Language production is the process by which people express their thoughts through language. There are two kinds of "language": spoken and written, and spoken language is also called speech production (Zhang Qingfang \& Yang Yufang, 2003).

The production of speech is mainly reflected in the accuracy of pronunciation of words and sentences (Corrigall \& Trainor, 2014; Hille, Gust, Bitz, \& Kammer, 2011). Research on music training and speech production has produced different results in different populations. Bugos and Mostafa (2011) found in the undergraduate population that the music training group's speech production test scores were significantly better than the non-music training group. In addition, Register et al. (2007) conducted a follow-up study of children with speech impairments and found that the speech training ability of the music training group has been significantly improved. However, in the study of children aged 5-6 (Tsang \& Conrd, 2011), 8-9 years old (Hille, Gust, Bitz \& Kammer, 2011), and the elderly (Hanna-Pladdy \& MacKay, 2011), music training did not have a significant impact on speech production ability.

Researchers are also exploring further in the second language. For example, in a study of Finnish college students, it was found that subjects with high musical ability were significantly better at listening to English words than those with lower musical ability (Milovanov, Pietilä, Tervaniemi, \& Esquef, 2010). However, a study of Indian children showed that there was no significant difference in the pronunciation of English words between the music training group and the non-music training group (Swaminathan \& Dopinath, 2013).

Written language refers to the use of words to express one's thoughts and feelings, including the correct writing and writing of words (Du Yanping, 2008). As early as 1994, Douglas and Willatts explored the relationship between musical ability and literacy. The study found that there is a positive correlation between individual spelling ability and music rhythm resolution. The results were also validated in children with dyslexia (Overy, Nicolson, Fawcett \& Klarke, 2003) and primary school students (Hille, Gust, Bitz \& Kammer, 2011).

It can be seen that music training promotes the production of language, which improves the ability of speech production and written language to some extent. However, there are still research differences and vacancies in this area. For example, whether music training has an impact on Chinese spelling needs further verification. 


\subsection{Music training and speech memory}

Speech memory is one of the prerequisites for language learning and an important cognitive ability in language processing (Baddeley A., 2003; Duyck W, Szmalec A, Kemps E, 2003). Therefore, improving speech memory ability is also an important part of learning language.

Ho, Cheung and Chan (2003) conducted horizontal and vertical studies among children aged 615 in Hong Kong. The results of the horizontal study show that children with music training experience have significantly better memory scores than children without music training experience. Longitudinal studies have shown that speech memory has improved even more in children who have undergone one year of music training. Considering the variable of material presentation, Mei Leilei et al. (2008) explored the relationship between material presentation and speech memory. It was found that the memory performance of the music training group was significantly better than that of the non-music training group, and the children's memory effect on the song and rhythm presentation materials was significantly better than that presented in the way of reading.

The above studies were based on specialized music training, and Rickard, Nikki, Jorge, Anneliese and Samia (2010) examined the impact of the school's basic music curriculum on speech memory. It was found that after the music course, students performed better in learning and instantly recalling verbal information, but there was no significant change in visual memory. In addition, researchers explored the differences between visual and auditory memory between musicians and non-musicians. In terms of memory music, musicians performed better than nonmusicians, but there was no significant difference in memory pictures (Cohen et al., 2011).

All the above studies have consistently proved that music training has a positive impact on verbal memory. However, a study of patients with Alzheimer's disease found that at the beginning of the study, music interfered with the memories of the participants, and after repeated practice, the way of singing can retain more memory (Moussard, Bigand, Belleville, \& Peretz, 2012). Domestically, Lai Shuxian and Zhang Wei (2010) found that in the context of classical music, the memory effect is better in the study of college students. In non-classical music environments, music training has a hindrance to memory effects.

Researchers have also explored the reasons behind the impact of music training on verbal memory. In both normal conditions and speech suppression, Franklin, Sledge, Jonides, Rattray, and Moher (2008) found that adults who had music training under normal conditions were significantly better than adult speech memory without music training, but under the conditions of speech suppression, this advantage does not exist. This result was then verified in the study by Franziska Degé and Gudrun Schwarzer (2017).

The above studies show that music has different effects on speech memory. When music and memory tasks are performed simultaneously, the music training experience does not have a significant impact, and those memory tasks performed after music training will show the effect of music training. So it is not yet possible to determine whether there is a causal relationship between music training and verbal memory.

\section{Deficiency and outlook}

Most of the previous studies are related research, so whether there is a causal relationship between music training and language ability, more research is needed to verify.

Music training includes instrumental training and non-instrumental training (eg, vocal music, etc.), but in previous studies there was no clear distinction between the two types of music training. In the future, researchers can improve this.

The effect of music training on phonological awareness is different in English, German and Chinese groups. Differences in language may also be the cause of differences in music training 
effects. Then, this requires more researchers to explore the relationship between music training and Chinese learning.

The length of music training time has produced different effects in normal children and children with language problems, so the length of time that music training has an effect on language ability should be further clarified.

\section{References}

[1] Du Yanping. (2008). The impact of early written language training on the development of children's follow-up learning ability_-Taking the investigation of Hangzhou urban primary school as an example. (Doctoral dissertation, Central China Normal University).

[2] Jiang Cunmei. Cognitive Psychology [M]. Shanghai: East China Normal University Press. 2016:198

[3] Lai Shuxian, \& Zhang Wei. (2010). The influence of music on the memory effect of Chinese words. Chinese Journal of Health Psychology, 18(9), 1110-1112.

[4] Li Wenhui, Suo Changqing, Dan Fei, \& Zhou Tingting. (2016). The impact of music training on the phonological awareness of children aged 5-6 years. Chinese Journal of Child Health, 24(6), 668-669.

[5] Margaret Matlin. Cognitive Psychology [M]. Li Yongna Translated. Beijing: Mechanical Industry Press, $2016: 28$

[6] Mei Leilei, Li Yanfang, Long Zhishan, Chen Chuansheng, \& Dong Qi. (2008). The influence of material presentation on Chinese children's English and Chinese language memory with different music training experience. Acta Psychologica Sinica, 40(8), 883-889.

[7] Wang Mengyuan,Ning Ruiwei,Zhang Xueyan.Music Training Delays Speech Awareness Ageing[J].Advances in Psychological Science,2015,23(01):22-29.

[8] Zhang Qingfang \& Yang Yufang. (2003). Theory of vocabulary access in speech production. Progress in Psychological Science, 11(1), 6-11.

[9] BaddeleyA. Workingmemory and language: an overview. Journal of Communication Disorders, 2003, 36: 189 208

[10] Bugos, J., \& Mostafa, W. (2011). Musical training enhances information processing speed. Bulletin of the Council for Research in Music Education, 187, 7-18.

[11] Chan A S, HoY C, CheungM C. Music training improves verbal memory. Nature, 1998, 396(12): 128 129

[12] Chobert, J., Marie, C., François, C., Schön, D., \& Besson, M. (2011). Enhanced passive and active processing of syllables in musician children. Journal of Cognitive Neuroscience, 23(12), 3874-3887.

[13] Cohen, M. A., Evans, K. K., Horowitz, T. S., \& Wolfe, J. M. (2011). Auditory and visual memory in musicians and nonmusicians. Psychonomic Bulletin \& Review, 18(3), 586-591.

[14] Corrigall, K. A., \& Trainor, L. J. (2014). Associations between length of music training and reading skills in children. Music Perception, 29(2), 147-155.

[15] Degé, F., \& Schwarzer, G. (2017). Music lessons and verbal memory in 10- to 12-year-old children: investigating articulatory rehearsal as mechanism underlying this association. Psychomusicology Music Mind \& Brain, 27(4), 256266.

[16] Douglas, S., \& Willatts, P. (1994). The relationship between musical ability and literacy skills. Journal of Research in Reading, 17(2), 99-107.

[17] DuyckW, SzmalecA, KempsE, et a.l Verbalworkingmemory is involved in associativeword learning unless visual codes are available. Journal ofMemory and Language, 2003, 48: 527 541

[18] Escalda, J., Lemos, S. M., \& França, C. C. (2011). Auditory processing and phonological awareness skills of fiveyear-old children with and without musical experience. Jornal Da Sociedade Brasileira De Fonoaudiologia, 23(3), 258-263.

[19] Flaugnacco, E., Lopez, L., Terribili, C., Montico, M., Zoia, S., \& Schön, D. (2015). Music training increases phonological awareness and reading skills in developmental dyslexia: a randomized control trial. Plos One,10(9), e0138715.

[20] Franklin, M. S., Sledge Moore, K., Yip, C. Y., Jonides, J., Rattray, K., \& Moher, J. (2008). The effects of musical training on verbal memory. Psychology of Music, 36, 353-365. http://dx.doi.org/10.1177/ 0305735607086044

[21] Goswami, U. (2011). Language music and children's brains: A rhythmic timing perspective on language and music as cognitive systems. Language and Music as Cognitive Systems.

[22] Habib, M., Lardy, C., Desiles, T., Commeiras, C., Chobert, J., \& Besson, M. (2016). Music and dyslexia: A new musical training method to improve reading and related disorders. Frontiers In Psychology, 7

[23] Hanna-Pladdy, B., \& MacKay, A. (2011). The relation between instrumental musical activity and cognitive aging. Neuropsychology, 25(3), 378-386.

[24] Hille, K., Gust, K., Bitz, U., \& Kammer, T. (2011). Associations between music education, intelligence, and spelling ability in elementary school. Advances in Cognitive Psychology, 7(1), 1-6. 
[25] HoY C, CheungM C, ChanA S. Music training improves verbal butnot visualmemory: Cross sectional and longitudinal explorations in children. Neuropsychology, 2003, 17: 439 450

[26] Kempert, S., Götz, R., Blatter, K., Tibken, C., Artelt, C., \& Schneider, W., et al. (2016). Training early literacy related skills: to which degree does a musical training contribute to phonological awareness development?. Frontiers in Psychology, 7(7), 1803.

[27] Lathroum, L. M. (2011). The role of music perception in predicting phonological awareness in five-and six-yearold children. Dissertations \& Theses - Gradworks, 130.

[28] Long, M. (2014). 'I can read further and there's more meaning while I read': An exploratory study investigating the impact of a rhythm-based music intervention on children's reading. Research Studies in Music Education, 36(1), $107-124$.

[29] Lowe, A. S. (1995). The effect of the incorporation of music learning into the second-language classroom on the mutual reinforcement of music and language (Unpublished doctorial dissertation). University of Illinois at UrbanaChampaign.

[30] Manon, G., Cooper, F. E., \& Griffiths, T. D. (2013). Auditory temporal-regularity processing correlates with language and literacy skill in early adulthood. Cognitive Neuroscience, 4(3-4), 225-230.

[31] Milovanov, R., Pietilä, P., Tervaniemi, M., \& Esquef, P. A. A.(2010). Foreign language pronunciation skills and musical aptitude: A study of Finnish adults with higher education. Learning and Individual Differences, 20(1), 56-60.

[32] MOUSSARD, A., BIGAND, E., BELLEVILLE, S., \& PERETZ, I. (2012). Music as an aid to learn new verbal information in Alzheimer's disease. Music Perception, 29, 521-531. DOI: 10.1525/

[33] Overy, K., Nicolson, R. I., Fawcett, A. J., \& Clarke, E. F. (2003). Dyslexia and music: Measuring musical timing skills. Dyslexia, 9(1), 18-36.

[34] Parbery-Clark, A., Anderson, S., Hittner, E., \& Kraus, N. (2012a). Musical experience offsets age-related delays in neural timing. Neurobiology of Aging, 33(7), 1483. e1-1483. e4.

[35] Parbery-Clark, A., Anderson, S., Hittner, E., \& Kraus, N. (2012b). Musical experience strengthens the neural representation of sounds important for communication in middle-aged adults. Frontiers in Aging Neuroscience, 4, 30, doi: 10.3389/fnagi.2012.00030

[36] Parbery-Clark, A., Tierney, A., Strait, D. L., \& Kraus, N. (2012). Musicians have fine-tuned neural distinction of speech syllables. Neuroscience, 219, 111-119.

[37] Patscheke, H., Degé, F., \& Schwarzer, G. (2016). The effects of training in music and phonological skills on phonological awareness in 4- to 6-year-old children of immigrant families. Frontiers in Psychology, 7(94), 1647.

[38] Register, D., Darrow, A.-A., Swedberg, O., \& Standley, J. (2007). The use of music to enhance reading skills of second grade students and students with reading disabilities. Journal of Music Therapy, 44(1), 23-37.

[39] Rickard, Nikki S.|Vasquez, Jorge T.|Murphy, Fintan|Gill, Anneliese|Toukhsati, Samia R. (2010). Benefits of a classroom based instrumental music program on verbal memory of primary school children: a longitudinal study. Australian Journal of Music Education, 1(1), 12.

[40] Schellenberg, E. G. (2004). Music lessons enhance IQ. Psychological Science, 15(8), 511-514.

[41] Schellenberg, E. G. (2011). Examining the association between music lessons and intelligence. British Journal of Psychology, 102(3), 283-302.

[42] Swaminathan, S., \& Gopinath, J. K. (2013). Music training and second-language English comprehension and vocabulary skills in Indian children. Psychological Studies, 58(2), 164-170.

[43] Swaminathan, S., \& Schellenberg, E. G. (2017). Musical competence and phoneme perception in a foreign language. Psychonomic Bulletin \& Review, 24(6), 1-6.

[44] Tallal, P., \& Gaab, N. (2006). Dynamic auditory processing, musical experience and language development. Trends in Neurosciences, 29(7), 382-390.

[45] Tanaka, A., \& Nakamura, K. (2004). Auditory memory and proficiency of second language speaking: A latent variable analysis approach. Psychological Reports, 95(3), 723-734.

[46] Tierney, A. T., \& Kraus, N. (2013). The ability to tap to a beat relates to cognitive, linguistic, and perceptual skills. Brain \& Language, 124(3), 225-31.

[47] Tsang, C. D., \& Conrad, N. J. (2011). Music training and reading readiness. Music Perception, 29(2), $157-163$.

[48] Tunmer, W. E. \& M. L. Herriman. 1984. The development of metalinguistic awareness: A conceptual overview [C]MW. E. Tunmer et al. Metalinguistic Awareness in Children: Theory, Research and Implications. New York: Springer-Verlag: 12-35.

[49] White-Schwoch, T., Carr, K. W., Anderson, S., Strait, D. L., \& Kraus, N. (2013). Older adults benefit from music training early in life: Biological evidence for long-term training-driven plasticity. The Journal of Neuroscience, 33(45), $17667-17674$. 